УДК 347.447.72:614.4

https://doi.org/10.24866/1813-3274/2021-1/126-133

А. К. Гайнутдинов ${ }^{1}$, Казанский (Приволжский) федеральный университет,

г. Казань, Россия

E-mail: tasiktten1@rambler.ru

\title{
КОРОНАВИРУС КАК ОБСТОЯТЕЛЬСТВО НЕПРЕОДОЛИМОЙ СИЛЫ И ОСНОВАНИЕ ДЛЯ ЗАКУПКИ ТОВАРОВ, РАБОТ И УСЛУГ У ЕДИНСТВЕННОГО ПОСТАВЩИКА
}

Аннотацุия. В статье описывается один из способов заключения государственного контракта в условиях непреодолимой силы, вызванной новой коронавирусной инфекцией. Доказано, что новая коронавирусная инфекция является обстоятельством непреодолимой силы, спровоцировавшим нестабильную экономическую ситуацию, в условиях которой система государственных закупок является инструментом регулирования социально-экономических процессов, роль которой трудно переоценить. Обоснована возможность заключения государственного контракта в целях ликвидации последствий новой коронавирусной инфекции у единственного поставщика, в то же время указывается на имеющиеся недостатки такого способа заключения государственного контракта.

Ключевые слова: коронавирус, эпидемия, снабжение медицинской продукцией, государственный контракт, контрактная система, закупка у единственного поставщика, коррупциогенный фактор, Федеральная антимонопольная служба России, обстоятельство непреодолимой силы, закупка.

1 Гайнутдинов Адэль Камилевич, соискатель кафедры гражданского права юридического факультета Казанского (Приволжского) федерального университета, г. Казань, Россия.

Для циттирования: Гайнутдинов А. К. Коронавирус как обстоятельство непреодолимой силы и основание для закупки товаров, работ и услуг у единственного поставщика // Азиатско-Тихоокеанский регион: экономика, политика, право. 2021. № 1. С. 126-133. https://doi.org/10.24866/1813-3274/2021-1/126-133.

(C) Гайнутдинов А. К., 2021 
Adel K. Gainutdinov ${ }^{1}$, Kazan (Volga) Federal University, Kazan, Russia

E-mail: tasikitten1@rambler.ru

\section{CORONAVIRUS AS A FORCE MAJEURE EVENT AND THE REASON FOR THE PURCHASE OF GOODS, WORKS AND SERVICES FROM A SINGLE SUPPLIER}

Abstract. The article describes one of the ways to conclude a government contract in conditions of force majeure caused by a new coronavirus infection. It is proved that the new coronavirus infection is a force majeure circumstance that provoked an unstable economic situation in which the public procurement system is a tool for regulating socioeconomic processes, and its role is very significant. The possibility of concluding a state contract in order to eliminate the consequences of a new coronavirus infection with a single supplier is substantiated, at the same time, the existing shortcomings of this method of concluding a state contract are pointed out.

Keywords: coronavirus, epidemy, supply of medical products, government contract, contract system, purchase from a single supplier, corruption factor, Federal Antimonopoly Service of Russia, force majeure, purchase.

История кризисов показывает, что социальные и экономические потрясения обнажают давно существующие, назревшие проблемы общества, требовавшие решения задолго до их наступления. Не является исключением и нынешняя сложная социально-экономическая обстановка, выявляя остроту проблемы реализации конституционных принципов сбалансированности бюджета, бюджетной дисциплины, а также рационального и эффективного расходования бюджетных средств.

Конституцией Российской Федерации закреплено, что человек, его права и свободы являются высшей ценностью. Сохранение жизни и здоровья человека является первоначальной, основной гарантией государства.

Это конституционное положение основывается на общепризнанных принципах и нормах международного права, закреплённых в важнейших нормативных правовых актах: Всеобщей декларации прав человека 1948 г., Международном пакте о гражданских и политических правах 1966 г., Международном пакте об экономиче-

${ }^{1}$ Gainutdinov Adel Kamilevich, Candidate of the Department of Civil Law of the Faculty of Law Kazan (Volga Region) Federal University, Kazan, Russia.

For citing: Gainutdinov A. K. Coronavirus as a force majeure event and the reason for the purchase of goods, works and services from a single supplier // PACIFIC RIM: Economics, Politics, Law. 2021. No 1 . P. 126-133. https://doi.org/10.24866/1813-3274/2021-1/126-133. 
ских, социальных и культурных правах 1966 г., Конвенции о защите прав человека и основных свобод 1950 г. и др.

11 марта гендиректор ВО3 сообщил, что распространение болезни, вызванной коронавирусом нового типа COVID-19, «может быть расценено как пандемия».

Согласно ст. 1 Федерального закона «О санитарно-эпидемиологическом благополучии населения» под эпидемией следует понимать инфекционные заболевания человека, характеризующиеся тяжёлым течением, высоким уровнем смертности и инвалидности, быстрым распространением среди населения.

Эпидемия, характеризующаяся распространением инфекционного заболевания на территории страны, территории сопредельных государств, а иногда и многих стран мира, называется пандемией (греч. pandemia - весь народ).

Это первая пандемия, причиной которой послужил коронавирус. Ранее в истории человечества пандемиями признавались вспышки чумы и холеры, свиного гриппа H1N1 и распространение ВИЧ-инфекции.

В указанных условиях перед государством особенно остро стоит вопрос об обеспечении эффективного функционирования системы снабжения медицинской продукцией и другими товарами первой необходимости.

Система государственных закупок является инструментом регулирования социально-экономических процессов, роль которого трудно переоценить в условиях нестабильной экономической ситуации.

Значение государственных контрактов для экономики нашей страны крайне велико, поскольку с их помощью удовлетворяются потребности государства в товарах, работах, услугах, то есть государственные контракты являются инструментом, с помощью которого государство выполняет свои социально-экономические функции.

Осуществление закупки, согласно положениям законодательства о контрактной системе, для заказчика является довольно трудоёмкой процедурой, а действующий Федеральный закон от 05.04.2013 №44-Ф3 «О контрактной системе в сфере закупок товаров, работ, услуг для обеспечения государственных и муниципальных нужд» (далее - Закон о контрактной системе) усложняет данный процесс, вводя определённые алгоритмы, критерии и ограничения [1].

В ст. 93 Закона о контрактной системе предусмотрены случаи, когда закупки могут быть совершены в обход конкурентных процедур.

В п. 9 ч. 1 ст. 93 данного закона указано, что закупка у единственного поставщика может быть произведена в случае закупки определённых товаров, работ, услуг вследствие аварии, иных чрезвычайных ситуаций природного или техногенного характера, непреодолимой силы, в случае возникновения необходимости в оказании медицинской помощи в экстренной форме либо в оказании медицинской 
помощи в неотложной форме и если применение иных способов определения поставщика (подрядчика, исполнителя), требующих затрат времени, нецелесообразно.

Понятие обстоятельств непреодолимой силы раскрыто в положениях п. 3 ст. 401 «Основания ответственности за нарушение обязательства» части первой Гражданского кодекса Российской Федерации (далее - ГК РФ): если иное не предусмотрено законом или договором, лицо, не исполнившее или ненадлежащим образом исполнившее обязательство при осуществлении предпринимательской деятельности, несёт ответственность, если не докажет, что надлежащее исполнение оказалось невозможным вследствие непреодолимой силы, т.е. чрезвычайных и непредотвратимых при данных условиях обстоятельств; к таким обстоятельствам не относятся, в частности, нарушение обязанностей со стороны контрагентов должника, отсутствие на рынке нужных для исполнения товаров, отсутствие у должника необходимых денежных средств.

Применение приведённых положений разъяснено в п. 8 Постановления Пленума Верховного Суда Российской Федерации от 24 марта 2016 г. № 7 «О применении судами некоторых положений Гражданского кодекса Российской Федерации об ответственности за нарушение обязательств» : в силу п. 3 ст. 401 ГК РФ для признания обстоятельства непреодолимой силой необходимо, чтобы оно носило чрезвычайный и непредотвратимый при данных условиях характер;

требование чрезвычайности подразумевает исключительность рассматриваемого обстоятельства, наступление которого не является обычным в конкретных условиях;

если иное не предусмотрено законом, обстоятельство признается непредотвратимым, если любой участник гражданского оборота, осуществляющий аналогичную с должником деятельность, не мог бы избежать наступления этого обстоятельства или его последствий.

Как верно отмечал О. С. Иоффе, указание на чрезвычайный характер непреодолимой силы очень важно, ибо, соответствуя её объективной природе, оно ориентирует на недопустимость квалификации в качестве непреодолимой силы любого жизненного факта [2, с. 430].

Некоторые учёные раскрывают признак чрезвычайности, указывая на его масштабность [3, с. 80], необычайную мощь проявления [4, с. 306].

Относительно признака непредотвратимости в цивилистике также не достигнуто понимания. Одни учёные исходят из непреодолимости обстоятельств для конкретного причинителя вреда с учётом имеющихся у него возможностей [2, с. 431; 5 , с. 178]. По мнению других юристов, явление будет относиться к непреодолимой силе, если оно непредотвратимо для любого лица, с учётом уровня развития науки и техники всего общества [6, с. 122; 7, с. 283].

При оценке непредотвратимости представляется возможным использовать компромиссный подход, суть которого заключается в необходимости учёта не 
только возможностей конкретного должника, но и возможностей однородных лиц и организаций по роду и условиям деятельности [8, с. 245-246].

Таким образом, учитывая скорость и масштабы распространения новой коронавирусной инфекции (COVID-19), а также характер её происхождения, представляется возможным признать её обстоятельством непреодолимой силы.

Министерство финансов Российской Федерации в Письме от 19.03.2020 № 2406-06/21324 «Об осуществлении закупок у единственного поставщика (подрядчика, исполнителя) при введении режима повышенной готовности» сообщило, что распространение новой коронавирусной инфекции, вызванной 2019-NCOV, носит чрезвычайный и непредотвратимый характер, в связи с чем является обстоятельством непреодолимой силы. Учитывая, что распространение новой коронавирусной инфекции, вызванной 2019-NCOV, является обстоятельством непреодолимой силы, заказчик вправе осуществить закупку у единственного поставщика на основании пункта 9 части 1 статьи 93 Закона № 44-ФЗ. При этом условие об отсутствии закупаемых товаров, работ, услуг в перечне товаров, работ, услуг, необходимых для оказания гуманитарной помощи либо ликвидации последствий чрезвычайных ситуаций природного или техногенного характера, утверждённое распоряжением Правительства Российской Федерации от 30.09.2013 г. № 1765-p, не подлежит применению в связи с введением режима повышенной готовности.

Федеральная антимонопольная служба России также Письмом от 18.03.2020 №ИA/21684/20 сообщила, что в связи с пандемией коронавирусной инфекции (COVID-19) указанная ситуация является обстоятельством непреодолимой силы, что необходимо учитывать при рассмотрении жалоб, дел об административных правонарушениях, обращений о включении в реестр недобросовестных поставщиков и проведении проверок. При этом ФАС России также обращает внимание, что в соответствии с пунктом 9 части 1 статьи 93 Закона 44-Ф3 закупки определённых товаров, работ, услуг вследствие непреодолимой силы могут осуществляться у единственного поставщика.

В вышеуказанном письме ФАС России подчёркивает, что закупки, направленные на профилактику, предупреждение и ликвидацию последствий распространения COVID-19 могут осуществляться у единственного поставщика при условии наличия причинно-следственной связи между действиями по профилактике, предупреждению, ликвидации последствий распространению коронавирусной инфекции и предметом такой закупки.

Несомненно, при необходимости ликвидации опасности для жизни и здоровья людей, принятии мер по обеспечению их медицинской помощью требуется оперативность и нет времени для проведения конкурентных процедур. Действия и заказчиков, и поставщиков продиктованы крайней необходимостью, и это оправданно.

Являясь наиболее простым по возможности и времени реализации способом, закупка товаров, работ и услуг из единственного источника на сегодняшний день и 
так является наиболее распространённым способом закупки. В нынешних же условиях для предотвращения чрезвычайной ситуации его роль возрастёт многократно.

Однако данный способ закупки не лишён существенных недостатков, касающихся прозрачности, конкуренции и эффективности расходования бюджетных средств.

Ещё дореволюционные российские цивилисты отмечали, что государство действует не само собой, а через известные органы, и опыт показывает настоятельную потребность точно определить органам государства образ действия при заключении договоров, особенно таких, на которые идёт значительная часть государственного достояния [9, с. 298-299].

Как было указано М. В. Мишустиным на Оперативном совещании с вице-премьерами, состоявшемся 23.03.2020, «на поддержку медицинской и фармацевтической промышленности мы направили более 23 млрд рублей буквально за эти два дня».

В кризисных условиях усиливается необходимость рационального и эффективного расходования бюджетных средств. Между тем при осуществлении закупки у единственного поставщика в силу естественного отсутствия конкуренции не представляется возможным добиться снижения цены по сравнению с первоначально заявленной, а значит - и сэкономить средства бюджета. В связи с чем возникают опасения относительно существенного завышения стоимости контрактов.

Кроме того, в условиях финансово-экономического кризиса и преодоления его последствий существенную роль могут играть государственные заказы. Конкуренция в госзакупках и возможность получения госконтрактов для многих малых и средних компаний были одной из немногих возможностей «держаться на плаву». Заказчик же, закупая товары, работы или услуги у заранее определённого лица, как правило, монополиста в той или иной сфере, не стимулирует предпринимателей, что может негативно сказаться на развитии экономического потенциала государства.

Как указывала Л. Г. Каранатова, «в целом федеральная контрактная система призвана стать в сфере государственных закупок важнейшим антикоррупционным институтом, направленным на укрепление экономического партнёрства государства и бизнеса» $[10$, с. 240]. Постоянный же выбор одного и того же контрагента, по верному замечанию Н. А. Курц, является мощным коррупциогенным фактором, возникающим в связи с угрозой складывания неформальных потенциально коррупционных связей между представителями заказчика и единственного такого контрагента [11, с. 113].

При этом Н. А. Курц подчёркивает, что в указанных условиях единственным антикоррупционным механизмом остается обязанность заказчика согласовывать или уведомлять контролирующий орган о закупках из единственного источника, причём заказчик обязан обосновать невозможность (нецелесообразность) использования иных способов осуществления закупок, расчёт цены контракта и иные существенные его условия. 
Невозможно не согласиться с автором, что указанные механизмы априори не являются достаточно эффективными и призваны скорее дополнить другие средства контроля за государственными и муниципальными заказчиками.

Представляется, что в сложившейся ситуации дальнейшая оценка обоснованности применения заказчиками категории «непреодолимая сила» при осуществлении закупок у единственного поставщика в тех или иных случаях будет осуществляться преимущественно в ходе судебного разбирательства в рамках судебного контроля.

Таким образом, контрактная система закупок играет особую роль в условиях нестабильной экономической и социальной ситуации в стране, направленную на своевременное удовлетворение государственных нужд, и результатом функционирования такой системы закупок в конечном итоге должно являться эффективное выполнение государством своих социально-экономических функций.

\section{Список литературы}

1. Федякина, О. В. Осуществление закупки у единственного поставщика / О. В. Федякина. - Москва : Право Доступа, 2017. - URL: http://base.garant.ru/77709919/ (дата обращения: 15.03.2021).

2. Иоффе, О. С. Избранные труды : в 4-х т. Т. 1 / О. С. Иоффе. - СанктПетербург, 2003. - 572 с.

3. Exner, A. Der Begriff der hoheren Gewalt (vis maior) im romischen und im heutigen Verkehrsrecht / A. Exner. - Aalen, 1970. - 86 s.

4. Яблочков Т. М. Понятие непреодолимой силы в гражданском праве // Юридические записки, издаваемые Демидовским лицеем. - Ярославль, 1911. Вып. II - III (VIII - IX). - C. 271-321.

5. Венедиктов, В. А. Договорная дисциплина в промышленности / В. А. Венедиктов. - Ленинград, 1935. - 212 с.

6. Агарков, М. М. К вопросу о договорной ответственности // Вопросы советского гражданского права. - Москва ; Ленинград, 1945. - С. 114-155.

7. Покровский, И. А. Основные проблемы гражданского права / И. А. Покровский. - Москва : Статут, 2003. - 353 с.

8. Градобоева, 3. В. Непреодолимая сила в гражданском праве России // Цивилистические записки. - Москва, 2002. - С. 245-246.

9. Мейер, Д. И. Русское гражданское право. Ч. 2 / Д. И. Мейер. - Москва, 1997. -449 c.

10. Каранатова, Л. Г. Управление жизненным циклом государственных закупок в Российской Федерации: переход к федеральной контрактной системе : учеб. пособие / Л. Г. Каранатова, А. Е. Кузьмин, А. М. Кузьмина. - СанктПетербург : ИПЦ СЗИУ РАНХиГС, 2012. - 316 с. 
11. Курц, Н. А. Порядок заключения договоров и структура договорных связей в государственных и муниципальных закупках : монография / Н. А. Курц. Москва : Юстицинформ, 2018. - 196 с.

\section{References}

1. Fedyakina O. V. Osushchestvlenie zakupki u edinstvennogo postavshchika [Procurement from a single supplier]. Moskow: Pravo Dostupa Publ., 2017. Available at: http://base.garant.ru/77709919/ (accessed 15 March 2021).

2. Ioffe O. S. Izbrannye trudy: v 4-kh t. T. 1 [Selected works: in 4 volumes. Vol. 1]. St. Petersburg, 2003. 572 p.

3. Exner A. Der Begriff der hoheren Gewalt (vis maior) im romischen und im heutigen Verkehrsrecht. Aalen, 1970. $86 \mathrm{~s}$.

4. Yablochkov T. M. Ponyatie nepreodolimoi sily v grazhdanskom prave [The concept of force majeure in civil law]. Yuridicheskie zapiski, izdavaemye Demidovskim litseem [Legal notes published by the Demidov Lyceum]. Yaroslavl, 1911, vol. II-III (VIII-IX), pp. 271-321.

5. Venediktov V. A. Dogovornaya distsiplina v promyshlennosti [Contractual discipline in industry]. - Leningrad, 1935. $-212 \mathrm{~s}$.

6. Agarkov M. M. K voprosu o dogovornoi otvetstvennosti [On the issue of contractual responsibility]. In: Voprosy sovetskogo grazhdanskogo prava [Questions of Soviet civil law]. Moscow; Leningrad, 1945, pp. 114-155.

7. Pokrovskii I. A. Osnovnye problemy grazhdanskogo prava [Basic problems of civil law]. Moscow: Statut Publ., 2003. 353 p.

8. Gradoboeva Z. V. Nepreodolimaya sila $\mathrm{v}$ grazhdanskom prave Rossii [Force majeure in civil law of Russia]. In: Tsivilisticheskie zapiski [Civilian notes]. Moscow, 2002, pp. 245-246.

9. Meier D. I. Russkoe grazhdanskoe parvo. Ch. 2 [Russian civil law. Part 2]. Moscow, 1997. $449 \mathrm{p}$.

10. Karanatova L. G., Kuzmin A. E., Kuzmina A. M. Upravlenie zhiznennym tsiklom gosudarstvennykh zakupok $v$ Rossiiskoi Federatsii: perekhod k federal'noi kontraktnoi sisteme: ucheb. posobie [Management of the life cycle of public procurement in the Russian Federation: transition to the federal contract system: textbook. allowance]. Sankt-Peterburg: IPTs SZIU RANKhiGS, 2012.316 p.

11. Kurts N. A. Poryadok zaklyucheniya dogovorov i struktura dogovornykh svyazei v gosudarstvennykh i munitsipal'nykh zakupkakh: monografiya [Procedure for the conclusion of contracts and the structure of contractual ties in state and municipal purchases]. Moscow: Yustitsinform Publ., 2018. 196 p. 